\title{
Deceleration Trauma to the Heart and Great Vessels after Road-traffic Accidents
}

M. J. GOGGIN, ${ }^{*}$ M.B., M.R.C.P. ; F. D. THOMPSON,† M.A., M.B., B.CHIR. ; J. W. JACKSON,‡ M.CH., F.R.c.s.

\section{British Medical fournal, 1970, 2, 767-769}

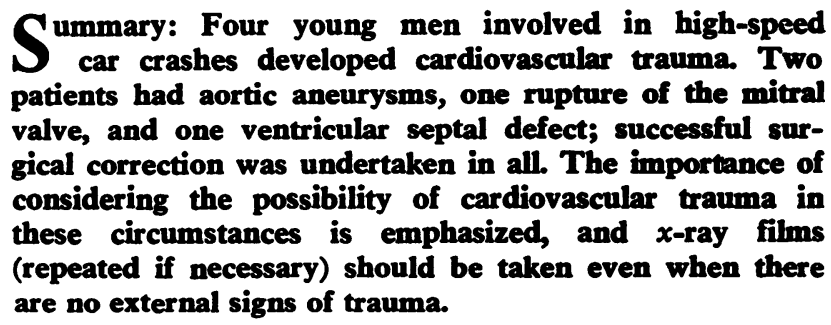

\section{Introduction}

The case histories are presented of four young men who were involved in road-traffic accidents. All were high-speed injuries, with vehicles travelling between 30 and 60 miles (48 and $96 \mathrm{~km}$.) per hour. In two cases the impact speeds were between 90 and 100 miles (145 and $160 \mathrm{~km}$.) per hour. As a result the heart and great vessels were subjected to sudden deceleration; the subsequent injuries are described.

\section{Case Histories}

Case 1.-A man aged 21 received bilateral femoral fractures in 1965, when involved in a motorcycle accident. His anterior chest wall was bruised, and an $x$-ray film showed a contusion in the left lung (Fig. 1). In 1968, at a mass miniature $x$-ray examination, a rounded shadow with a well-defined margin was noted arising from below the aortic knuckle (Fig. 2). There were no clinical signs sug-

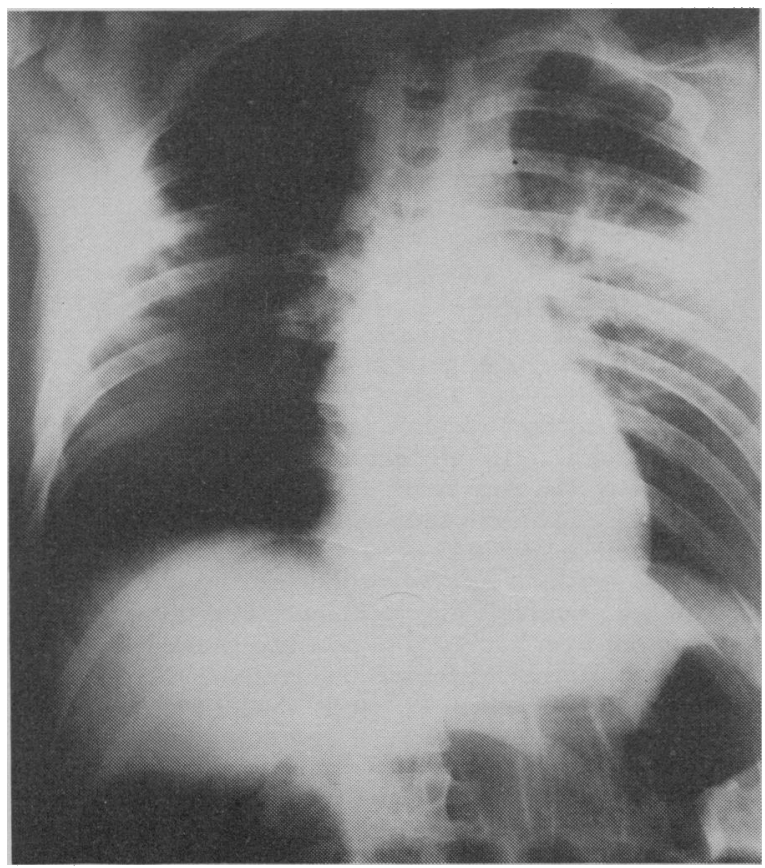

FiG. 1.-Case 1. Chest radiograph at time of accident, showing a patchy opacity in left mid-zone, but no abnormality of mediastinum

*Lecturer in Nephrology, Institute of Urology, London W.C.2. Formerly Cardiological Registrar, Harefield Hospital, Harefield, Middlesex.

†Medical Registrar, St. Philip's Hospital W.C.2. Formerly Cardiological Registrar, Harefield Hospital, Harefield, Middlesex.

‡Consultant Thoracic Surgeon, Harefield Hospital, Harefield, Middlesex.

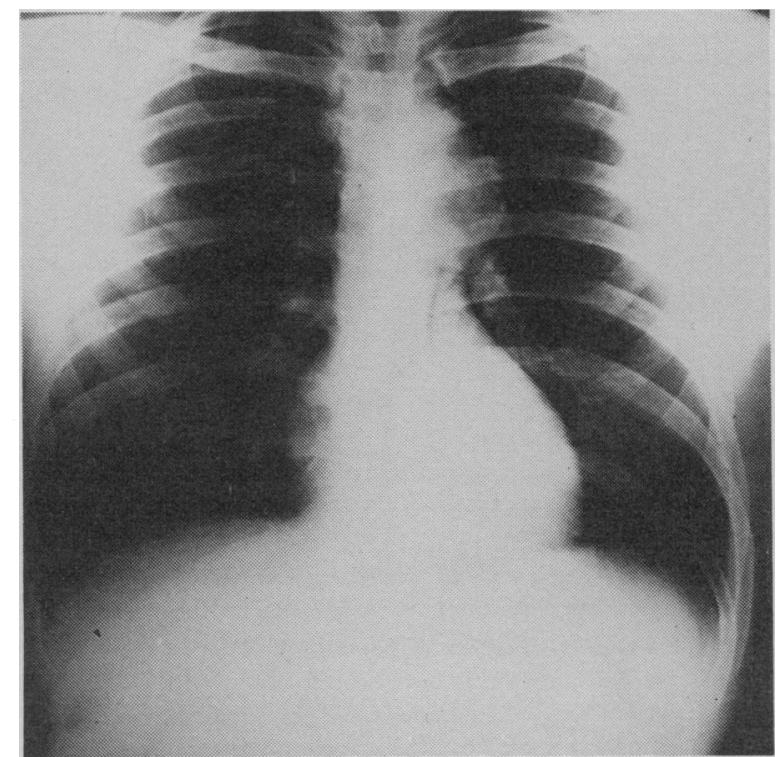

FIG. 2.-Case 1. Chest radiograph following the mass miniature $x$-ray examination, showing presence of an aneurysm in descend-

$$
\text { ing thoracic aorta. }
$$

gestive of an aortic aneurysm. Subsequent angiography (Fig. 3) showed this to be in the descending thoracic aorta. At operation a fusiform 3 -in. $(7 \cdot 5-\mathrm{cm}$.) long aneurysm arising just distal to the left subclavian artery was found. The aorta was completely

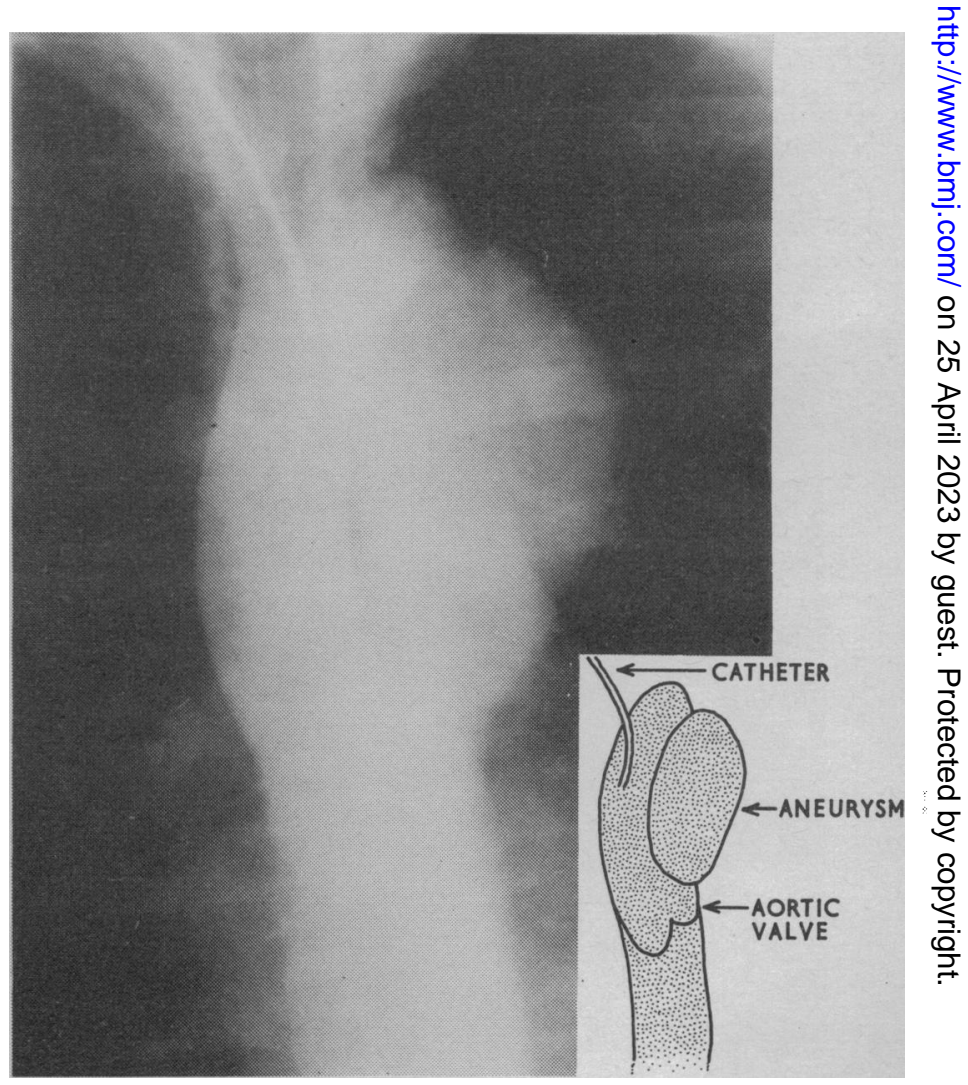

Fig. 3.-Case 1. Frame of the posteroanterior angiogram confirming site of aneurysm. 
transected with the development of a false sac. The aneurysm was resected and a Dacron graft inserted (Fig. 4), left atrio-femoral bypass being used. Postoperative progress was satisfactory.

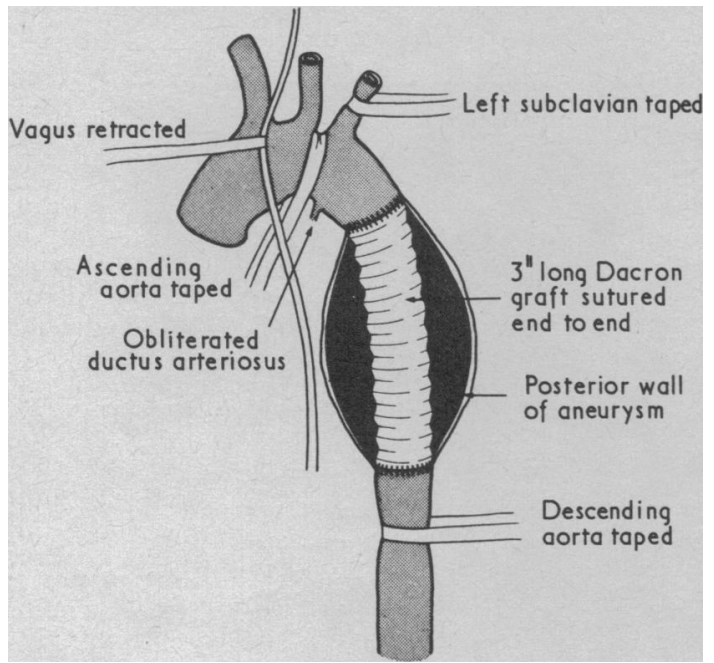

Fig. 4.-Case 1. Diagram of operative findings and repair.

Case 2.-A 21-year-old man was involved in a head-on car crash in 1967. His systolic blood pressure was $60 \mathrm{~mm}$. $\mathrm{Hg}$ and he required immediate resuscitation. He had a right hemiparesis. Chest $x$-ray examination on admission showed bilateral fractures of the second and third ribs and a widened mediastinal shadow (Fig. 5). The probability of a ruptured aorta was considered on the night of admission. For five weeks he improved and the hemiparesis recovered. Six weeks after the accident the blood pressure was $150 / 80 \mathrm{~mm}$. Hg and a systolic murmur could be heard all over the precordium. Peripheral pulses were equal. Angiography confirmed the presence of the aneurysm (Fig. 6). Four months after the accident the aneurysm was resected and a Dacron graft inserted (Fig. 7), a bypass from the left atrial appendix to the descending thoracic aorta being used. The aneurysm began just below the origin of the left subclavian artery and was the result of a complete transection with the formation of a lobulated false fibrous sac.

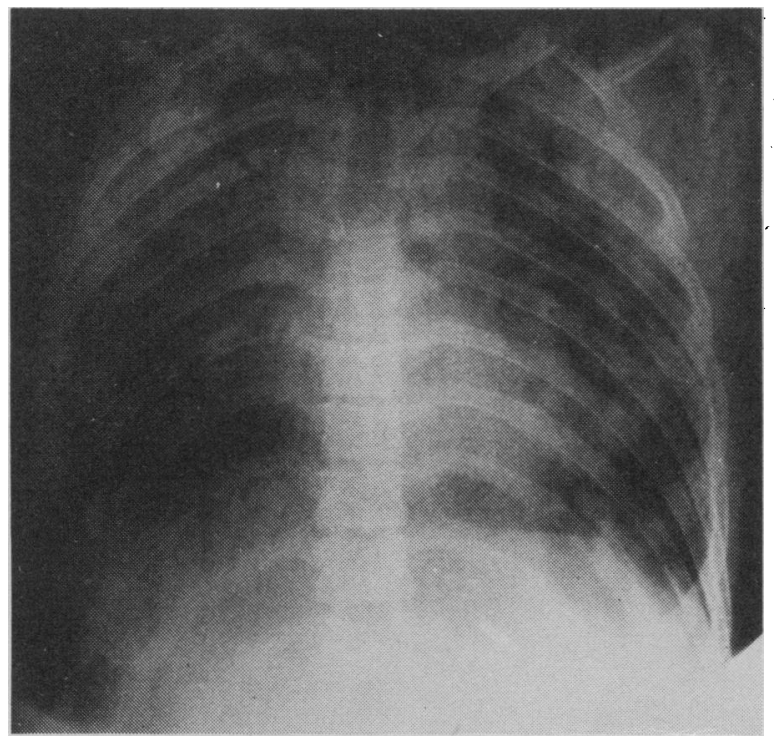

FIG. 5. - Case 2. Chest radiograph on night of accident, showing a widened mediastinum and patchy opacities in both lung fields.

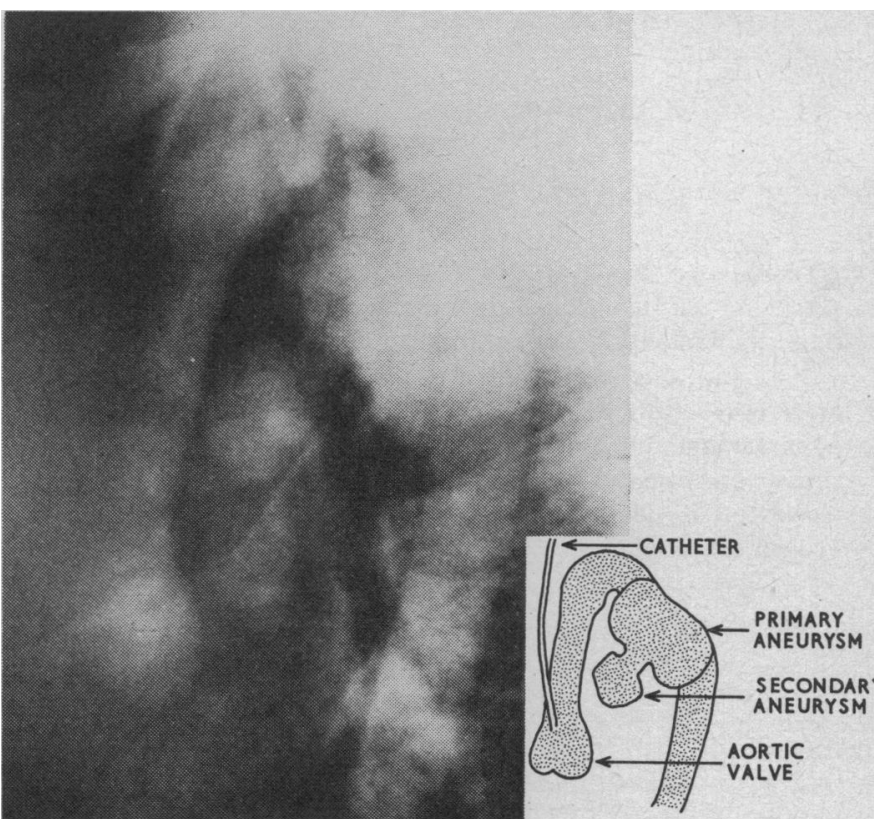

FIG. 6.-Case 2. Lateral angiogram showing site of aneurysm with presence of a secondary aneurysm.

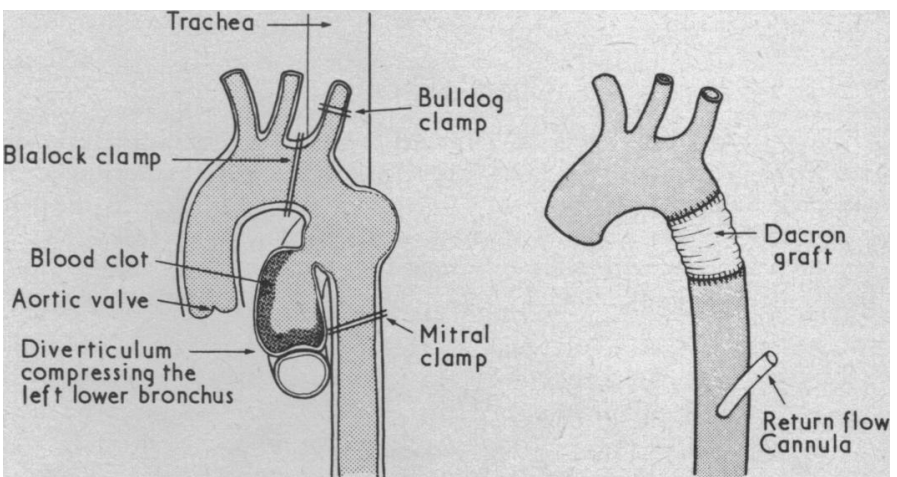

Fic. 7.-Case 2. Diagram of operative findings and repair.

Case 3.-The car that this 27-year-old man was driving ran into the back of a stationary vehicle. His left clavicle was fractured, as were his left second and third ribs. His blood pressure was 95/70 and he was dyspnoeic. A pansystolic murmur was heard in the mitral area and there was a short diastolic murmur. The chest $x$ ray film confirmed the fractures and was compatible with a left haemopneumothorax. An electrocardiogram showed inverted T waves in V 4-6. He was resuscitated and chest drainage tubes were inserted. Comparison with earlier medical records suggested that the murmur heard was of recent origin. The clinical diagnosis of mitral incompetence was confirmed by left atrial pressure studies, using a transbronchial technique. For the next two years he was symptom-free, but serial $x$-ray films showed that the transverse diameter of the heart was increasing. The cardiothoracic ratio on 8 April 1963 was 0.49 , on 19 August 19630.51 , and on 23 March 19640.52 . At operation there was a normal anterior cusp and the posterior cusp was split, with detached chordae. Five years after operation he was symptom-free, but on digoxin and a thiazole diuretic, and in March 1970 he was admitted with a Streptococcus viridans endocarditis.

Case 4.-A 16-year-old male back-seat passenger was injured in a head-on collision. When examined clinically and radiologically no signs of injury or other abnormality were found. Twenty-four hours later he was noted to have a heart rate of 150 in sinus rhythm, a blood pressure of $95 / 70$, a left sternal edge systolic thrill, and a loud pansystolic murmur associated with a prominent third heart sound. Cardiac catheterization confirmed the ventricular septal defect with a flow ratio of 3 to 1 . It was hoped that 
his failure could be controlled medically for three months to allow the defect to develop firm fibrous margins, but within five weeks he deteriorated. At operation a defect near the apex of the right ventricle was repaired with a Teflon patch, faced with pericardium.

\section{Discussion}

At a time when the incidence of high-speed road-traffic accidents is increasing, we have detailed three instances where, following resuscitation, injury to the heart and great vessels became apparent. In the fourth case the signs developed 24 hours after the accident. Rice and Wittstruck (1951) stated that the aorta ruptures because the thoracic part continues to travel forwards while the arch is tethered. Greendyke (1966) reviewing the results of necropsies in 218 car accidents, found aortic rupture in $16 \%$. He included these in a detailed review of 42 cases. The commonest site of rupture of the thoracic aorta ( $50 \%$ of cases) was the isthmus, immediately distal to the origin of the subclavian artery, at the insertion of the ductus arteriosus. The aortic hiatus of the diaphragm and the ascending aorta just superior to the valve were found to be the other important sites. In 14 cases aortic rupture was the major cause of death, but in 28 cases it was accompanied by other serious and potentially lethal trauma. Thirty-four cases had a simple laceration while the remaining eight had multiple tears. Complete transection occurred in 20 cases. Where patients were involved in road-traffic accidents most of the car occupants were young adults, while pedestrians were mostly past middle life.

In the very early cases it could be argued that angiography to delineate the tear would introduce delay and the dangers of further extension trauma. In cases diagnosed some time from the original accident the argument for full investigation is very strong. In accident departments the possibility of trauma to the aorta should be considered. Patients complain of chest pain and shortness of breath. $X$-ray films, including a penetrated film, should be taken, even if there are no external signs of trauma. A widened upper mediastinum is a suspicious sign. A further $x$-ray film may be necessary after two to three hours if there is doubt or the clinical state demands it. The electrocardiogram may show signs of myocardial damage, a previously known axis may be changed, or a low-voltage may suggest tamponade.

Traumatic mitral incompetence seems to be a rare injury. McLaughlin et al. (1964) surveyed 18 cases from the English literature. In discussion, a review of 546 cases of blunt trauma was quoted, in which no case of isolated mitral valve disease is listed. In mitral valve injury papillary muscle rupture or avulsion is the usual lesion. The patient is shocked, dyspnoeic, cyanosed, and has chest pain. Murmurs may or may not be present at this stage. If failure is absent then it soon develops, while if the patient does not die in the first hour then he is able to compensate and the subsequent course is that of valvular heart disease. This is in contrast to patients with post-infarctive papillary muscle in incompetence, who generally deteriorate rapidly (Craddock and Mahe, 1953) because of associated myocardial damage. In the diagnosis serial $x$-ray films help, especially if a pre-trauma film is available. Post-traumatic pulmonary venous congestion is the rule. The electrocardiogram is abnormal but not specific.

Reviewing traumatic ventricular septal defect Pollock et al. (1952) found 12 cases of isolated septal rupture. Cary et al. (1958) described the case (among four) of a patient who lived 52 hours and had no external signs of crush injury, bruising, or fractured ribs. The electrocardiogram had shown changes compatible with muscle death, injury, and ischaemia, and a conduction defect suggestive of right bundle-branch block. The phase of ventricular systole when the injury occurred was important, and this has also been shown experimentally (Bright and Beck, 1935). Another possible mechanism of septal rupture is infarction following occlusive trauma to the coronary vessels.

Whatever the mechanism for these injuries, we feel it is important that the processes described above should be borne in mind when dealing with high-speed trauma, as following the initial resuscitation period such conditions are often apparent, and with the advances of surgical technique a total correction can often be performed.

We wish to thank Dr. Walter Somerville for his valuable criticism and the photographic and medical illustration departments of the Institute of Urology for preparing the photographs and diagrams.

\section{REFERENCES}

Bright, E. F., and Beck, C. S. (1935). American Heart foumal, 10, 293. Cary, F. H., Hurst, J. W., and Arentzen, W. R. (1958). New England fournal of Medicine, $\mathbf{2 5 8}, 355$

Craddock, W. L. and Mahe, G. A. (1953). Fournal of the American Medical Association, 151, 884

Greendyke, R. M. (1966). Fournal of the American Medical Association, $195,527$.

McLaughlin, J. S., Cowley, R. A., Smith, G., and Matheson, N. A (1964). Fournal of Thoracic and Cardiovascular Surgery, 48, 261. Pollock, B. E., Markelz, R. A., and Shuey, H. E. (1952). American Heart fournal, 43, 273.

Rice, W. G., and Wittstruck, K. P. (1951). Fournal of the American Medical Association, 147, 915 .

\title{
Effect of Pregnancy on Sebum Excretion
}

\author{
J. L. BURTON, ${ }^{*}$ B.SC., M.R.C.P. ; W. J. CUNLIFFE, ${ }^{*}$ B.SC., M.R.C.P. ; D. G. MILLAR,† $\|$ F.R.C.s., M.R.c.o.G. \\ SAM SHUSTER, $\ddagger$ PH.D., F.R.C.P.
}

British Medical fournal, 1970, 2, 769-771

\begin{abstract}
Cummary: Sebum excretion rates from forehead skin were measured serially during and after pregnancy in 10 normal women. Only minor fluctuations occurred during the middle and last trimesters of pregnancy, but there was a pronounced decrease in the postpartum period.
\end{abstract}

\footnotetext{
*Senior Registrar, University Department of Dermatology, Royal Victoria Infirmary, Newcastle upon Tyne.

+ Senior Lecturer, University Department of Obstetrics, Princess Mary Maternity Hospital, Newcastle upon Tyne.

₹ Professor of Dermatology, University of Newcastle upon Tyne.

Now Professor of Human Reproduction and Obstetrics, Southampton General Hospital, Southampton.

$\S$ Now Consultant Dermatologist, the General Infirmary, Leeds.
}

Probably a powerful sebotrophic factor is present in pregnancy, but its nature is conjectural.

\section{Introduction}

Some of the factors controlling human sebaceous gland activity have been identified by observing the effect of exogenous hormones given to normal and castrated subjects (Strauss and Pochi, 1963). Little is known, however, of the sebaceous response to some more common endocrinological upheavals such as those due to pregnancy. The flurry of metabolic and 